\title{
UM LEGADO DO SÉCULO XX PARA A POLÍTICA EDUCACIONAL DO SÉCULO XXI: A TEORIA DO CAPITAL HUMANO
}

\author{
Letícia Carneiro Aguiar \\ Universidade do Sul de Santa Catarina - Unisul \\ leticia.aguiar@unisul.br
}

\begin{abstract}
RESUMO
O artigo analisa os referenciais teóricos da política educacional brasileira na década de 1960, relacionando-os com os referenciais adotados pela mesma na atualidade. Intenciona demonstrar como algumas configurações estabelecidas para a educação naquela década ainda constituem um legado educacional que persiste nas políticas educacionais dos anos de 1990. Novamente há uma recuperação do raciocínio economicista para justificar os ajustes e reformas que atingem as políticas públicas, sendo mantidas matrizes teóricas que reforçam as noções de desenvolvimento como progresso, aliado ao investimento em recursos humanos, e o binômio educação e desenvolvimento é colocado na centralidade das políticas educativas.

Palavras-chave: Educação e Desenvolvimento; Política Educacional; Teoria do Capital Humano

\section{A LEGACY OF THE TWENTIETH CENTURY FOR THE EDUCATIONAL POLICY OF THE TWENTY-FIRST CENTURY: THE HUMAN CAPITAL THEORY}

\begin{abstract}
This article analyzes the theoretical frameworks of the Brazilian educational policy in the 1960s, linking them to the practices that are prevalent today. It aims to demonstrate how some settings for education in that decade are an educational legacy that still persists in the educational policies of the 1990s. Again, there is a recovery of economic reasoning to justify the adjustments and reforms that affect public policies, theoretical frameworks that reinforce the concepts of development and progress, coupled with investment in human resources, persist, and both education and economic development continue to be placed at the center of educational policies.
\end{abstract}

Keywords: Education; Development; Educational Policy; Human Capital Theory.

\section{Introdução}

$\mathrm{O}$ artigo tem como objetivo refletir como um dos principais fundamentos teóricos da política educacional brasileira da década de 1960, a Teoria do Capital Humano (TCH), também se encontra presente na política dos anos de 1990. Utilizando-se de parte de um estudo (AGUIAR, 2008) realizado sobre a política educacional do estado de Santa Catarina dos anos 1960, procura-se demonstrar como algumas configurações teóricas estabelecidas para a educação, no contexto de um projeto societário de ideologia desenvolvimentista e modernização conservadora, constituem um legado educacional que persiste nas políticas educativas adotadas no Brasil a partir dos anos de 1990.

Nos anos de 1960, a política educacional brasileira passou a ser pensada como integrante dos planos econômicos globais e, como política pública, voltou-se para atuar na correlação de forças sociais, seguindo determinações do desenvolvimento econômico 
capitalista. O binômio educação e desenvolvimento foi estrategicamente planejado, aprovando-se medidas legais num esforço comprometido com a necessidade de ordenar e normalizar a questão educacional, incorporando-a aos preceitos da ideologia desenvolvimentista presente no projeto econômico nacional. Neste momento, a Teoria do Capital Humano constitui-se no principal estatuto teórico da política educacional implantada. Desde a década de 1990, nos marcos do Consenso de Washington ${ }^{1}$ e das reformas do Estado brasileiro, as políticas públicas são redirecionadas para atender demandas de uma economia mundializada, sob a égide do projeto societário neoliberal.

Nas reformas educacionais, a partir de 1990, a TCH é re-significada ocorrendo uma associação entre educação e empregabilidade, e preconiza-se que a escolarização amplia as possibilidades de inserção dos indivíduos no mercado de trabalho. Sustentadas nesta ótica, as reformas têm o entendimento de que os modelos e perfis exigidos na formação pelo paradigma da produção capitalista (flexibilidade e polivalência profissionais) estão direcionados para formar indivíduos dinâmicos e adaptáveis às demandas e às mudanças no mundo do trabalho.

\section{A educação na concepção da Teoria do Capital Humano}

A TCH teve como principal expoente Theodoro W. Schultz (1902-1998), idealizador da idéia de capital humano nos anos 50, nos EUA. Para Schultz, o trabalho humano quando qualificado pela educação é um dos principais meios de aumento de produtividade e, por conseqüência, dos lucros do capital. Capital humano é por ele compreendido como a soma dos investimentos do indivíduo em aquisição de conhecimentos (capital este adquirido em sua quase totalidade nas escolas e universidades) e que a qualquer momento reverte em benefícios econômicos para o próprio indivíduo (por exemplo, na posse de melhores empregos e vantagens na aquisição de novas aprendizagens para o mercado de trabalho) (SCHULTZ, 1962).

Essa Teoria chega ao Brasil num contexto bastante tomado pela ideologia nacionaldesenvolvimentista nos anos de 1950, defensora da crença na forte presença do Estado como agente propulsor do desenvolvimento, identificando a planificação econômica como uma ferramenta fundamental para o alcance do desenvolvimento econômico eficiente.

O desenvolvimentismo foi a ideologia da burguesia industrial latino-americana, que acreditava que o desenvolvimento e o subdesenvolvimento não são fenômenos qualitativamente distintos, mas sim, são "expressões quantitativamente diferentes do processo histórico de acumulação do capital" (OLIVEIRA, 2000, p. 201). E a TCH, ao contribuir largamente para a difusão da crença na eficácia da educação como instrumento de distribuição de renda e equalização social, faz da educação um instrumento indispensável aos países subdesenvolvidos para alcançar o desenvolvimento pretendido.

No âmbito nacional, a partir dos anos de 1940 a política econômica brasileira foi se moldando à associação com o capital financeiro internacional, consoante com o plano do pós-guerra de imposição de uma nova ordem mundial. O processo de industrialização sob a égide do capital estrangeiro, visto como solução alternativa de desenvolvimento econômico intensifica-se na década seguinte, inaugurando-se um novo modelo de industrialização.

Neste contexto, molda-se um novo cenário para a educação brasileira e, a partir do que determinava a Constituição de 1946, sobre a competência da "União legislar sobre as diretrizes e bases da educação nacional", elabora-se um projeto de reforma geral da educação. Nesse quadro, em 1961, foi aprovada e sancionada a primeira Lei de Diretrizes e 
Bases da Educação Nacional (LDBEN), a Lei 4.024/61. No âmbito educacional formula-se a tese da educação como instrumento de desenvolvimento social.

É assim que, no Brasil, a TCH ganha força nos anos 60 em virtude de uma preocupação cada vez maior com o crescimento econômico e melhor distribuição de renda. A educação sendo considerado um elemento dinâmico do processo de desenvolvimento passa a ser integrada a política redistributiva da renda. Tal política começa pelo investimento social nos recursos humanos e pela efetiva oportunidade de acesso a educação. "Sob o influxo dessa concepção de educação, passa-se então a admitir a idéia de planejamento impondo dessa forma ao Estado funções complexas" (CRUZ, 2008, p. 3).

Partindo da premissa central de que o homem educado produz mais, a TCH afirma que a educação adquirida (representada por novas habilidades e maior capacidade produtiva) se incorporaria ao homem como seu "capital", aumentando sua capacidade de gerar renda. Dentro desse raciocínio, os trabalhadores são considerados capitalistas porque, através de investimentos na aquisição de habilidades e conhecimentos, eles têm capacidades economicamente valiosas. A teoria procura, portanto, dissolver a oposição capital-trabalho, tentando convencer o trabalhador de que ele não é dono da força de trabalho, mas sim dono de um novo tipo de capital, tão necessário ao desenvolvimento quanto o capital financeiro.

A Teoria também sugere que os pobres só permanecem na sua condição de pobreza porque lhes faltam os conhecimentos que os tornariam produtores mais hábeis e, conseqüentemente, melhorariam seus rendimentos. Afirma que a educação será capaz de transformar uma pessoa de baixa qualificação em uma de qualificação mais alta. E, mais ainda, que uma vez alcançada melhor qualificação, seria reduzida a oferta total de trabalhadores pouco qualificados. Logo, a educação determinaria uma distribuição melhor da renda, pois aqueles que melhorassem de nível seriam mais bem pagos e os que permanecessem na condição primeira também teriam seus salários aumentados devido à diminuição da oferta de "mão-de-obra barata".

A valorização que a TCH faz da escola é no intuito de que ela é caminho para a mudança das condições individuais de vida, ao mesmo tempo em que beneficia a todos na sociedade. Portanto, se a possibilidade de ascensão social está baseada no mérito individual, a educação passa a ser um instrumento para a mudança dos padrões de mobilidade social. E se, na sociedade o que vai definir a posição social de cada indivíduo são as capacidades inatas desenvolvidas pela via educacional, os sucessos e os fracassos são transferidos aos próprios indivíduos.

Ao compreender a renda como resultante da produtividade, a diferença dos rendimentos entre os indivíduos é explicada pela diferença de capacidade de produção, sendo a educação considerada como o melhor instrumento de distribuição mais eqüitativa de oportunidades e de rendas. A educação seria, assim, um meio de ascensão social que permitindo a mobilidade dos indivíduos no interior da estrutura social, funcionaria como o grande motor do desenvolvimento e do progresso técnico e humano.

Essa concepção de educação filia-se a uma corrente de pensamento - a liberal, que apregoa ser a riqueza e a pobreza conseqüências naturais do esforço e do mérito individual de cada um. Pressupondo-se a existência de igualdade de direitos e oportunidades para que todos desenvolvessem suas "potencialidades", o bom cidadão é o indivíduo que consegue prosperar na vida. Esta não é igualdade de condições materiais, pois os indivíduos são diferentes entre si, apresentando diferentes capacidades, talentos e atributos diversos. Logo, não podem ser iguais em riqueza. Neste caso, seria então muito natural que o sucesso social fosse alcançado por alguns e por outros não. Dessa forma, as desigualdades 
sociais geradas pela riqueza, pelo nível sócio-econômico, ou melhor, pela propriedade privada e pela apropriação dos meios de produção, desigualdades que foram geradas pela ordem econômica capitalista e pelo regime jurídico-político burguês, são mascaradas.

Quanto à educação, Warde (1984) já afirmava que no século XX a burguesia ensaiou um de seus modelos de democracia, o qual chamou de "modelo democracia desenvolvimentista". Este modelo estava assentado na idéia de que o empobrecimento progressivo da classe trabalhadora tornava-a perigosa; "como conseqüência, era preciso pensar um mecanismo de participação e melhoria das condições de vida que suavizassem sua periculosidade. Era preciso neutralizar os embates com a força oponente" (WARDE, 1984, p. 61).

A burguesia pautou-se por esse modelo não por razões humanitaristas e pacifistas, mas sim porque o mesmo "a instrumentou adequadamente para a manutenção e ampliação da hegemonia" (WARDE, 1984), tendo em vista que o mesmo apoiava-se na crença da melhoria da sociedade e na correção das distorções de toda ordem, pela via da educação dos indivíduos, sendo a escola atribuída a função da reconstrução social.

Para a concepção liberal, a finalidade primordial da educação é a preparação do indivíduo para ocupar o seu lugar na sociedade, não se questionando sobre as implicações dos determinantes sócio-estruturais da educação. Afirma-se, assim, que os indivíduos, através da educação, devem desenvolver suas capacidades e aptidões individuais, o que legitima e sustenta desta forma a idéia de que a escola tem o papel de preparar os indivíduos para desempenharem os papéis sociais requeridas por uma sociedade de classes. A escola cumpre, assim, sua função de reguladora social, distribuindo os indivíduos pelas diversas ocupações e meios de vida em que se dividem as atividades humanas.

Para Saviani (1985), ocorre uma inversão idealista e ingênua da educação: de elemento determinado a educação torna-se elemento determinante da estrutura social. Uma inversão ideológica que reinterpreta e transverte as origens, o funcionamento e os objetivos do processo educativo real, e que faz a separação entre a teoria social e a realidade social, os problemas da educação são vistos como tendo autonomia, a-historicidade, isolados do contexto social e teorizados num sistema ideal", sistema este que mascara as desigualdades sociais advindas da divisão do trabalho, pela apropriação do capital e das forças produtivas.

A TCH, sob o estatuto epistemológico do positivismo e do pensamento liberal clássico, concebe o cidadão educado como aquele indivíduo que dotado de certo nível instrucional, desenvolve habilidades e capacidades que lhe permitem assumir determinados papéis sociais que colaboram com a manutenção da ordem e do progresso social. $\mathrm{O}$ cidadão educado é, portanto, o trabalhador disciplinado para atender as exigências de uma ordem econômica e social onde o capital subjuga o trabalho aos seus interesses e necessidades.

\section{A TCH na política educacional do Brasil da década de 1960: o caso catarinense}

A década de 1960 representou para Santa Catarina um marco no seu processo de modernização econômica. A ampliação e diversificação de sua base produtiva, a partir da segunda metade da década de 1940, quando começam a surgir elementos de um novo padrão de crescimento, encontram na década de 1960 uma forte intervenção estatal favorecedora da acumulação privada de capital. Nesse momento, ocorre uma profunda "politização das relações econômicas e a estruturação da ossatura material e institucional do Estado", a partir da implantação dos Planos de Metas do Governo - PLAMEG. (GOULARTI FILHO, 2002, p. 30). 
O capital industrial se consolidava e promovia, juntamente com as forças oligárquicas no comando do aparelho governamental, a integração produtiva em Santa Catarina. O golpe militar de 1964, apoiado pela oligarquia catarinense, ao procurar emudecer a oposição e acentuar o exercício da coerção, possibilitou determinadas condições para que governantes e seus aliados concretizassem políticas favorecedoras do desenvolvimento do capital, da concentração de renda e da ampliação das desigualdades sociais.

O aparelho governamental foi desafiado a modernizar-se e, pela primeira vez na história do estado, utilizou-se da técnica do planejamento com o objetivo de desenvolver e articular as políticas públicas para atender às exigências do modo de produção capitalista. $\mathrm{E}$ foi justamente o pretexto de modernizar o sistema educacional para responder às necessidades do desenvolvimento desse modo de produção, que as questões educacionais passaram a ser enfrentadas numa perspectiva global. $O$ binômio educação e desenvolvimento constituiu-se no eixo das políticas de modernização do Estado.

No âmbito estadual, a integração da educação aos planos econômicos globais PLAMEG, foi estrategicamente planejada com a criação do Conselho Estadual de Educação (CEE) - Lei 2.975/61, das Leis do Sistema Estadual de Ensino - Lei 3.191/63 e Lei 4.394/69, do Plano Estadual de Educação (PEE) 1969-1980 - Decreto 8.828/69, da Universidade para o Desenvolvimento do Estado de Santa Catarina (UDESC) - Decreto 2.802/65, e da realização de reformas no aparelho estatal e nos diferentes níveis do sistema escolar. Esse conjunto de leis e decretos se constituiu em medidas legais num esforço comprometido com a necessidade de ordenar e normalizar a questão educacional, incorporando-a aos preceitos da Lei de Diretrizes e Bases da Educação Nacional (Lei 4.024/61) e da Lei da Reforma Universitária (Lei 5.540/68), e à ideologia desenvolvimentista presente no projeto econômico nacional e estadual.

$\mathrm{O}$ acentuado desenvolvimento econômico em curso produziu o aumento da população urbana no estado que, de uma população até então predominantemente rural, passou a ser marcada pelo predomínio do urbano. Houve um aumento do leque de empregos, principalmente nos setores secundários e terciários, expressando a necessidade do letramento, do avanço da escolarização. Amplia-se a rede escolar, sobretudo, a do nível primário. Por conta da necessidade de serem formados professores para o primeiro nível da escolarização, expandiram-se a rede escolar de nível médio, principalmente, as Escolas Normais. Assim, os anos 60 se constituíram num marco fundamental para a construção de uma política de Estado para a educação catarinense.

Segundo Goularti Filho (2002), é somente a partir da segunda metade dos anos de 1940 que se inicia em Santa Catarina o período de ampliação e diversificação do capital industrial, pois até então sua economia tinha uma baixa capacidade de acumulação, desintegração econômica e falta de aporte financeiro. No período de 1945 a 1962 ocorreu uma consistente diversificação e ampliação da base produtiva na economia catarinense, decorrente do surgimento de novos setores (papel, papelão, pasta mecânica, cerâmico, metal-mecânico, plástico, materiais elétricos e indústrias ligadas ao setor de transporte), e começa a se realizar uma transição do complexo agro-comercial para o agroindustrial. Inicia-se um processo de metamorfose do capital - a economia agrária, extrativista e mercantil desdobrou-se no capital industrial e agroindustrial.

No entanto, "o movimento de ampliação e diversificação da base produtiva sofria constantes limitações, como falta de energia, recursos financeiros, infra-estrutura viária e portuária, mão-de-obra qualificada", limitações estas que reforçavam a desarticulação econômica do Estado (GOULARTI FILHO, 2002, p. 175). Tal caracterização desagradava sobremaneira, aos grupos econômicos e políticos locais, pois colocava o estado numa 
posição periférica em relação ao centro econômico capitalista mais desenvolvido do país a Região Sudeste. É nesse contexto que aqui se define o novo e mais significativo período da economia catarinense, o estatal industrial.

Nesse momento, o Estado brasileiro sistematicamente começa a utilizar-se da técnica do planejamento, e pouco a pouco vai associando os conceitos de "planejamento" e "desenvolvimento". O discurso desenvolvimentista passa a ser efetivamente assumido pelos governantes catarinenses no início dos anos 60, pois aqui encontrou condições objetivas propícias para tal, na medida em que ocorria, então, uma "crise de acumulação", e as condições materiais exigiam novas formas superiores de organização capitalista, pensada a partir do Estado para liberar as forças produtivas que entravavam o processo de acumulação.

Em nível local, formou-se, por parte do empresariado, dos políticos e dos técnicos a consciência de que as questões relativas ao desenvolvimento não poderiam ficar restritas ao governo federal, devendo o governo estadual assumir uma ampla tarefa no que se referia à formulação de metas e execução de programas no âmbito do planejamento econômico. O "empresariado catarinense, ao reconhecer a sua impossibilidade de dar continuidade à acumulação de capital", por conta e riscos próprios, "chama pela intervenção estatal para superar sua crise" (MICHELS, 1998, p. 185-186). É nesta perspectiva que o aparelho governamental começou a ser reestruturado para responder aos reclames da burguesia, e não poderia ser diferente, pois a composição do bloco no poder era de frações da própria classe dominante.

As sérias deficiências estruturais e institucionais existentes para que o capital pudesse avançar no seu processo de acumulação e concentração, fez com que o mesmo impusesse ao Estado a criação das condições necessárias à ampliação da acumulação privada. E entre os setores considerados prioritários para favorecer que tais condições ocorram, estava o setor educacional, devido à grande "carência de mão-de-obra preparada para o trabalho", segundo afirmava a Federação das Indústrias do Estado de Santa Catarina (FIESC, 1960).

As primeiras diretrizes para uma política educacional desenvolvimentista estadual são encontradas no Seminário Sócio-Econômico promovido pela FIESC nos anos de 19591960. O Seminário, que serviu de subsídios para a elaboração do Plano de Metas do Governo (PLAMEG I) de Celso Ramos (1960-1965), colocava em evidência os pontos de estrangulamento da economia catarinense. Um dos pontos levantados foi "a falta de elemento humano preparado para o trabalho", provando que havia um descompasso entre a demanda de mão-de-obra especializada que o processo econômico exigia e a deficiência do ensino. Era preciso, portanto, promover o ajustamento do ensino à política desenvolvimentista (FIESC, 1960, p. 7). Desse modo, ficava claro que a educação possuía parcela de responsabilidade durante o período de implantação e afirmação do "arranco desenvolvimentista", como preparadora de mão-de-obra. Para o governo do estado, a "valorização dos recursos humanos é um importante caminho para se chegar ao desenvolvimento da economia, pois esta não dependeria só dos capitais, mas da qualidade dos homens" (SANTA CATARINA, 1965, p.13).

No intuito de criar as condições necessárias para o aparelho governamental traçar as bases da política educacional catarinense e o planejamento global de suas ações nessa área, o governo de Santa Catarina realizou dois importantes convênios: o convênio entre o PLAMEG e o Centro de Estudos e Pesquisas Educacionais (CEPE) da UDESC e o convênio Ministério da Educação e Cultura (MEC), Instituto Nacional de Estudos 
Pedagógicos (INEP) e Organização das Nações Unidas para a Educação, a Ciência e a Cultura (UNESCO).

Estes convênios estavam inseridos numa política mais ampla do poder central, que no período de 1964 a 1968 firmou uma série de acordos (doze no total), conhecidos como “acordos MEC-USAID”. Esses acordos alcançaram o sistema educacional em todos os seus níveis e em todo o país, envolvendo aspectos voltados à reestruturação administrativa, planejamento e treinamento de pessoal docente e técnico.

Romanelli (2002) afirma que um agravamento da crise do sistema educacional, provocado pela aceleração do ritmo do crescimento da demanda social por educação, serviu para justificar a assinatura desses convênios, e serviram também de pretexto para assegurar a intervenção externa em forma de cooperação. A Agência Internacional dos Estados Unidos para o Desenvolvimento (USAID) assessorava a administração pública através de cooperação financeira e assistência técnica. Foram acordos que desencadearam uma reforma autoritária, vertical que vinculava o sistema educacional ao modelo econômico dependente, imposto pela política norte-americana para a América Latina. Como resultado desses acordos e de convênio firmado pelo MEC com a UNESCO, peritos estrangeiros assessoraram os estados na organização dos seus sistemas de ensino, auxiliando na elaboração de suas políticas educacionais.

O convênio PLAMEG-UDESC-CEPE, firmado em 1966, definiu como prioridade a realização de uma pesquisa que apontasse os problemas existentes no ensino primário e médio. Havia no período uma carência de dados sobre a realidade educacional catarinense, e o convênio procurava justamente financiar a realização de pesquisas. As pesquisas foram realizadas sob assessoria de Jacques Torfs e Michel Debrun, peritos da UNESCO integrantes das missões de planejamento educacional no Brasil, no período de abril de 1966 a março de 1968, e cujo relatório final recebeu o título "Sobre as Condições do Processo Educacional de Santa Catarina". O relatório chamava a atenção para o fato de que, considerando que Santa Catarina "está caminhando num processo irreversível de desenvolvimento", havia a necessidade de organização de elaboração de um planejamento integral da educação catarinense que, através da "colaboração de organismos nacionais e internacionais", faça o seu ajustamento "aos planos globais de desenvolvimento do Estado" e determine as modificações "estruturais e funcionais que se fazem necessárias na máquina administrativa responsável pelo controle e desenvolvimento da educação" (SANTA CATARINA, 1967, p. 152).

Além dessa pesquisa, outras duas também foram patrocinadas pelo PLAMEG e realizadas pelo CEPE entre os anos de 1966 e 1968: "Expansão da Escolaridade Primária até a 6 $6^{a}$ série" (1968) e "Evasão e Repetência nas Comunidades Pesqueiras" (1968). As pesquisas apontaram, entre outros aspectos: a descrença dos educadores na possibilidade de expansão da rede escolar, por esta estar em situação bastante precária, faltando professores, equipamentos e salas de aula; a insuficiência do serviço de assistência escolar e de escolas que oferecessem outras séries além do primário; a interferência do fator sócioeconômico na produção da evasão e repetência escolar; o fato da criança permanecer na escola enquanto não está capacitada a participar mais decisivamente das atividades produtivas; etc. (SANTA CATARINA, 1969a, 1968; 1967).

Para Dutra (1984, p. 39), as pesquisas parecem ter servido muito mais para justificar o "caráter de cientificidade" atribuído às mudanças realizadas pelo Plano Estadual de Educação e pela Lei do Sistema Estadual de Ensino em 1969 do que, de fato, serem úteis na orientação de uma política educacional que levasse em consideração as reais necessidades do povo catarinense. 
$\mathrm{O}$ fato de ter sido o estado brasileiro que realizou o primeiro diagnóstico da sua situação escolar, Santa Catarina foi habilitada para receber a assessoria técnica prevista no convênio MEC-INEP-UNESCO. Através desse convênio a assistência técnica estrangeira se fez presente em Santa Catarina à época da elaboração do Plano Estadual de Educação (PEE), principalmente quando da realização do IV Colóquio Estadual para a Organização do Sistema Estadual de Ensino (CEOSE), entre 5 a 8 de julho de 1967, em Florianópolis. O IV CEOSE reuniu técnicos e autoridades interessadas em educação, e desenvolveu estudos sobre a situação educacional catarinense.

Do convênio MEC-UNESCO resultaram os CEOSEs, realizados em vários estados brasileiros, tendo por objetivo tornar efetiva a existência dos sistemas estaduais de ensino criados pela Lei 4.024/61 e preparar as condições mediante as quais fosse possível aplicarse concretamente a LDBEN/61 e sua filosofia de descentralização. A descentralização acabou, pois, consistindo no objetivo principal do CEOSE que prestava assistência técnica aos estados na elaboração dos seus planos de educação, necessidade imperiosa para que fossem integrados aos ideais desenvolvimentistas da época. No convênio se afirmava que o plano educacional estadual deveria estabelecer metas e objetivos, em função das metas gerais do plano econômico, social e cultural da Nação, do Plano de Educação Nacional, dos planos econômicos, sociais e culturais do Estado.

$\mathrm{Na}$ área educacional, a descentralização fez a imposição das diretrizes concebidas no interior do poder central com a cooperação dos organismos internacionais, comprometidos que estavam com a ordem econômica dominante. Nesse sentido, o IV CEOSE se configurou num momento muito especial de articulação das principais idéias que nortearam os rumos da educação em Santa Catarina, seja na disseminação do conceito de planejamento como instrumento de inserção da educação nos ideais de desenvolvimento econômico, seja na definição do conteúdo pedagógico a ser contemplado no planejamento da educação.

Para que a descentralização ocorresse, o CEOSE defendia a necessidade dos Estados possuírem "líderes e técnicos suficientemente adestrados", pois o estudo e a gestão dos assuntos educacionais "não pode ser atribuição apenas de burocratas ou de técnicos, mas, sobretudo, de uma elite capaz de dar conteúdo real à educação" (SANTA CATARINA, 1967, p. 12). Além disso, eram objetivos do CEOSE: realizar diagnósticos e indicar medidas administrativas e técnicas que conduzam à implantação de novas estruturas ou mecanismos no sistema de educação do Estado e na organização das respectivas Secretarias de Educação; discutir idéias que devam lastrear a sua política de educação; orientar no planejamento educacional (BRASIL, 1967, p. 5).

Observa-se que nos debates promovidos pelo IV CEOSE a preocupação centrava-se no problema da queda da qualidade do ensino, sendo as causas da evasão e repetência escolar atribuídas não aos fatores econômicos, como diagnosticavam as pesquisas, mas sim à falta de socialização da criança, ao currículo considerado difícil e tradicional e a existência de professores não qualificados. Note-se que as problemáticas internas do sistema educacional e das escolas passam a ser tratados a partir de uma perspectiva mais técnica, mais "científica", condizente com a ideologia educacional da época, com contribuições importantes da Psicologia. Tais problemáticas são compreendidas não como questões relacionadas ao campo econômico-social, que ultrapassa o âmbito escolar, mas como aspectos de natureza estritamente psicológica e pedagógica. Logo, transformava-se a problemática da qualidade do ensino numa questão meramente individual, perdendo-se de vista as questões mais globais, mais amplas do processo escolar. Transferir os problemas 
da educação, sobretudo, para o âmbito do pedagógico e do psicológico retira do Estado a responsabilidade em relação às condições mais adequadas do ensino e, mesmo, para com a melhoria das condições de vida da população.

A política expressa na legislação do ensino e no planejamento global da educação teve seus contornos influenciados pela conjuntura econômica não somente estadual, mas também nacional. Essa política foi expressão dos debates e das propostas que já estavam sendo disseminadas pelo MEC com a colaboração dos organismos internacionais para o conjunto da sociedade brasileira. O debate e as propostas articulavam-se à idéia da contribuição que a educação poderia exercer no sentido de inscrever o Brasil no rol dos países desenvolvidos, referenciados que estavam na TCH.

A disseminação da "teoria" do capital humano, como panacéia da solução das desigualdades entre países desenvolvidos e subdesenvolvidos e entre os indivíduos, foi rápida nos países latino-americanos e de Terceiro Mundo, mediante os organismos internacionais (BID, BIRD, OIT, UNESCO, FMI, USAID, UNICEF) e regionais (CEPAL, CINTERFOR), que representam dominantemente a visão e os interesses do capitalismo integrado ao grande capital. (FRIGOTTO, 1995, p. 41)

O binômio "educação e desenvolvimento" estava presente nos principais documentos da política educacional catarinense dos anos de 1960: as Leis do Sistema Estadual de Ensino e o PEE. Veja-se, por exemplo, a função que cada um desses documentos atribuiu à educação: na Lei 3.191/61, Artigo 1º "à educação competia promover o desenvolvimento social, econômico, cultural e tecnológico", através da "preparação de recursos humanos necessários às novas demandas econômicas".

A educação, assim, contribuiria para fortalecer a "unidade nacional" e o "desenvolvimento integral da personalidade humana e a sua participação na obra do bem comum", preparando cada indivíduo para o domínio de recursos científicos e tecnológicos "que lhes permitam utilizar as possibilidades e vencer as dificuldades do meio"; na Lei 4.394/69, a educação competia, entre outras, "a formação e valorização de recursos humanos para o desenvolvimento econômico e social do Estado" (Artigo $1^{\circ}$ ); e no PEE a educação é vista como uma "área crucial [...] para se fundamentarem as várias etapas do 'arranco para o desenvolvimento', encarado no seu aspecto integral" (SANTA CATARINA, 1969b, p. 1).

No Plano, a educação teria além de um importante "valor espiritual" (preponderantemente, de formação moral e cívica), um valor econômico (meio de aceleração do desenvolvimento), sendo que "para atuar como determinante do processo de desenvolvimento e mudança" seriam seus objetivos: qualificar mão-de-obra qualificada necessária ao setor produtivo; elevar a renda individual e a conseqüente aquisição de novos hábitos de consumo; estabelecer novos padrões de mobilidade social; fornecer novos valores modificadores da visão de mundo tradicional; e estabelecer as condições necessárias à participação particular nos mecanismos institucionais, referentes às decisões da sociedade global. Dessa forma, entendia o PEE estar auxiliando a dinamizar a sociedade e a recompor o equilíbrio social. (SANTA CATARINA, 1969b, p. 3)

Nesse momento, torna-se cada vez mais freqüente um discurso governamental pautado nos temas do desenvolvimento, da modernização e da renovação como conteúdo mobilizador da sociedade e como justificativa para a deflagração das "reformas" educacionais. 
O discurso dos detentores do poder é, portanto, um discurso dissimulador das desigualdades entre as classes sociais. Os dominantes, como afirma Cunha (1980), em seus discursos lamentam as conseqüências dessa ordem econômica, deixando intocados, entretanto, os mecanismos que as produzem. Paralelamente, "[...] imaginam uma educação que venha subverter essa 'origem iníqua', esquecendo ou deixando de dizer que essa mesma educação, também pelos seus próprios mecanismos cotidianos, discrimina amplos setores sociais" (CUNHA, 1980, p. 57). Tal concepção de educação

[...] dissimula os seus próprios mecanismos de discriminação social, legitimando, então, essa discriminação; atrai, também, para si, a preocupação de setores descontentes da sociedade, que passam a vislumbrar a escola como instrumento de superação das condições materiais consideradas injustas; com isso, livra de críticas a ordem econômica e produz e reproduz essas condições. (CUNHA, 1980, p. 57)

\section{A Teoria do Capital Humano na política educacional brasileira dos anos de 1990}

Nos anos de 1980, o conceito de capital humano foi retomado pelos organismos multilaterais mais diretamente vinculados ao pensamento neoliberal, na área educacional, no contexto das demandas resultantes da reestruturação produtiva.

Encontramos nas agências multilaterais, Banco Mundial (BM), Banco Interamericano de Desenvolvimento (BID), UNESCO, Comissão Econômica para a América Latina e o Caribe (CEPAL), Organização Internacional do Trabalho (OIT), a concordância que o maior investimento na educação básica representa a única possibilidade real de reversão das desigualdades sociais. Contudo, contraditoriamente, a defesa de uma maior atenção à educação por parte destas instituições não vem acompanhada de uma reflexão crítica sobre as consequiências nefastas advindas da internacionalização econômica, na qual a maioria das nações do Terceiro Mundo participa subordinadamente. Desta forma, a apologia à competitividade - desenvolvida por essas instituições - expressa uma saída ideológica para uma situação de difícil resolução nas nações em desenvolvimento.

Em momentos anteriores, o que marcou o caráter das políticas educacionais no Brasil foi a vinculação das mesmas aos projetos desenvolvimentistas implementados em diversos governos. No momento atual, o teor destas políticas passa a ser definido pelo caráter de reestruturação do Estado, bem como da adaptação do sistema educacional aos imperativos do processo de globalização. Contudo, ainda que com características distintas, nesta nova fase das políticas educacionais, constata-se o incremento da influência de organismos internacionais, fortalecendo o seu poder de definir, direta e indiretamente, os rumos que devem ser seguidos pelo governo brasileiro nessa área.

Em comum acordo com o discurso que tende a se universalizar, estas instituições retomam o discurso presente na década de 1960 de que a qualificação - pela via da escolarização - garantiria aos indivíduos as condições para competirem no mercado de trabalho e melhorarem suas condições econômicas.

Entretanto, passadas algumas décadas, tornou-se fácil demonstrar a ineficácia destas proposições quando constatamos que a desigualdade social existente na sociedade brasileira não se explica, exclusivamente, por uma distribuição desigual do conhecimento, mas sim pelas próprias características deste modelo econômico que tende a concentrar, de forma contínua, a riqueza historicamente produzida. Os propagadores da TCH "esquecem" que o próprio acesso à produção cultural é reflexo das desigualdades geradas por este 
modelo de produção. Conseqüentemente, não poderia a educação corrigir aquilo que se edifica na própria estrutura econômica existente.

No Brasil, como um dos países signatários do Documento final da Conferência de Jomtien $^{2}$ na Tailândia, realizado em 1990, e pautado nas diretrizes estabelecidas pelos organismos internacionais, o discurso e a prática governamental afirmam a centralidade da educação no processo de elevação do país à categoria de "desenvolvido". Assiste-se novamente a reedição do binômio educação e desenvolvimento, que, sob o prisma do neoliberalismo, recupera idéias monetaristas que reforçam a necessidade do investimento em educação como fator de desenvolvimento. Essa relação entre educação e desenvolvimento está presente nos vários documentos das atuais políticas educativas que vêm sendo implementadas no Brasil, como parte das reformas educacionais em curso.

Desde então, a partir do governo de Fernando Henrique Cardoso (1995-2002), o país vivencia um intenso processo de reformas educacionais, expressos em ações e medidas que alteraram o objetivo das políticas, bem como a configuração do sistema. A política educacional vem sofrendo modificações nas suas orientações que, segundo Oliveira e Duarte (2005, p. 281), tendem "a responder às demandas crescentes de maior integração social das populações vulneráveis, ao mesmo tempo em que deve também formar a força de trabalho apta aos novos processos produtivos". A educação novamente passa a ser concebida com um importante instrumento de equalização social e distribuição de renda, pois o indivíduo investindo na sua formação aumenta sua capacidade de conquistar um emprego e tem um retorno econômico, gera maior renda e, assim, garante a sua sobrevivência.

O conjunto das reformas educativas engloba desde a implantação de uma nova LDBEN (Lei 9.394/96), de Parâmetros e Diretrizes Curriculares Nacionais para todos os níveis e modalidades de ensino, de um do Sistema Nacional de Avaliação da Educação Básica e Superior, de programas de gestão (Qualidade Total na Educação; Pró-Gestão); financiamento (Fundo de Manutenção e Desenvolvimento do Ensino Fundamental e Valorização do Magistério - FUNDEF, Fundo de Manutenção e Desenvolvimento da Educação Básica e Valorização dos Profissionais da Educação - FUNDEB, Programas de Renda Mínima (Bolsa Família, Bolsa Escola), até a ampliação da escolaridade obrigatória (educação fundamental de nove anos; educação básica obrigatória a partir de 2011).

Nesse período, seja na esfera pública ou privada ou nos diferentes segmentos sociais e nos documentos de política educacional, assiste-se a proliferação de idéias que concebem a educação como fator necessário à obtenção do emprego e o sucesso no mercado de trabalho. Dessa maneira, a educação novamente passa a ser vista com importante instrumento de equalização social e distribuição de renda.

O que antes era afirmado como imperativo para a mobilidade social, hoje se afirma como a única possibilidade de empregabilidade. Se antes, a questão centrava-se na possibilidade de mobilidade na estrutura social via educação, atualmente afirma-se como necessidade para a sua inclusão nessa estrutura. (OLIVEIRA, 2000)

Ressalta-se que o conceito "empregabilidade" se presta muito mais para encobrir do que explicar a realidade do crescimento da taxa de desemprego, do aumento significativo do emprego precário, da queda generalizada dos salários. Pois, sua definição refere-se a capacidade dos trabalhadores manterem-se empregados, encontrar novos empregos quando demitidos, na medida em que possuem a capacidade de responder aos requisitos de qualificação demandados pelo mercado de trabalho. É um conceito que ignora, por exemplo, que a natureza das inovações tecnológicas e organizacionais, juntamente com o reduzido crescimento econômico - próprio de uma fase do capitalismo caracterizada pela 
mais absoluta hegemonia do capital financeiro e, por decorrência, de sua lógica de funcionamento - determinam a existência de elevadas taxas de desemprego e a ampla disseminação de um processo de precarização do trabalho. No limite, cria-se uma grande massa de indivíduos dispensáveis, não exploráveis pelo capital; indivíduo cuja força-detrabalho não possui valor-de-troca no mercado, e cujo trabalho, de forma autônoma, não consegue nem mesmo se materializar em mercadorias vendáveis. (LEITE, 1997)

Portanto, o conceito de empregabilidade parte do falso pressuposto de que a causa do desemprego não é o desequilíbrio entre as dimensões da População Economicamente Ativa (PEA) e as ofertas de trabalho no contexto das atuais relações de trabalho e produção. A idéia de empregabilidade permite transferir ao trabalhador a responsabilidade pela sua condição de desempregado e/ou de vivência de condições precárias de trabalho, já que é o mesmo que não atende as demandas do mercado de trabalho que está exigindo maior e melhor qualificação e escolarização.

Destaca-se que três são os fenômenos, de dimensão mundial, que se entrelaçam e se complementam enquanto elementos determinantes do desemprego e da precarização do trabalho em escala planetária: o neoliberalismo, a reestruturação produtiva e a globalização.

Embora distintos quanto aos seus respectivos significados e momentos históricos que lhes deram origem, esses três fenômenos estão profundamente articulados no processo de transformações pelo qual vêm passando o capitalismo, desde o início dos anos 1970, com a crise do fordismo e o término do Acordo de Bretton Woods. Em decorrência dessas transformações, a relativa estabilidade de certo "modo de vida", estruturado a partir do pós-guerra nos países capitalistas centrais, e cuja característica maior é a existência de uma grande "rede de proteção ao trabalho e de segurança social ao cidadão", passou a ser fortemente abalada, dando origem a um sentimento generalizado de insegurança nas mais diversas esferas da sociedade. A confluência desses três fenômenos tem apontado para o agravamento da exclusão social em todo mundo, principalmente em países como o Brasil, mas também nos países desenvolvidos. (LIMA, 2007)

O Programa das Nações Unidades para o Desenvolvimento (PNUD), em seu Relatório Regional sobre Desenvolvimento Humano para a América Latina e o Caribe $2010^{3}$, intitulado "Atuar sobre o futuro: romper a transmissão intergeracional da desigualdade" (PNUD, 2010), constata que a desigualdade na América Latina é alta, persistente e ocorre em um contexto de baixa mobilidade social. Um dos aspectos mais dramáticos do relatório PNUD sobre o desenvolvimento humano dos países da América Latina não é a confirmação de que, no que se refere à distribuição da renda, a região continua sendo a mais desigual do planeta - mas a de que, apesar das melhoras dos últimos anos, o Brasil, na comparação com os demais países, tem a terceira pior situação do mundo. No caso brasileiro, a desigualdade de renda é a que mais pesa sobre o Índice de Desenvolvimento Humano - IDH - (queda de 22,3\%), seguido de educação (-19,8\%) e saúde $(-12,5 \%)$, segundo o cálculo, feito com base em números de 2008. Na América Latina a tendência é a mesma, mas com intensidade menor (queda de $18,8 \%$ na dimensão renda, $16,6 \%$ em educação e $12 \%$ em saúde).

Esses dados demonstram que as disparidades, além de serem um problema por si mesmas, têm efeitos graves no padrão de vida das pessoas. Na América Latina, o problema adquire contornos mais dramáticos por ter sobrevivido a uma série de políticas públicas ao longo das últimas décadas - desde as de perfil mais intervencionista, como nos anos 50, até as reformas de mercado nos anos 80 e 90 . A desigualdade de rendimentos, educação, saúde e outros indicadores persistem de uma 
geração à outra, e se apresenta num contexto de baixa mobilidade socioeconômica. (PNUD, 2010)

Na última vez que o PNUD divulgou o ranking de IDH, em outubro de 2009, o Brasil ocupava a $75^{\text {a }}$ posição com 0,813 (o IDH vai até 1). Uma queda de $19 \%$ tiraria o Brasil do grupo de países com desenvolvimento humano elevado. O Brasil continua entre os campeões das desigualdades sociais e econômicas na América Latina e Caribe. Segundo consta, $10 \%$ dos brasileiros mais pobres recebem $0,9 \%$ da renda do País, enquanto os $10 \%$ mais ricos ficam com 47,2\% da riqueza nacional (PNUD, 2010).

É esse o contexto sócio-político no qual são reeditadas teorias que reforçam o papel da educação no desenvolvimento econômico e na integração social, como uma alternativa para resolver os problemas de exclusão social e de desemprego, servindo para alimentar um modelo perverso e excludente de desenvolvimento. Reedita-se o raciocínio economicista da $\mathrm{TCH}$, que reduz a relação educação e emprego a uma questão de custobenefício. São matrizes teóricas que reforçam as noções de desenvolvimento como progresso, aliado ao investimento em recursos humanos, e concebem o cidadão educado como o indivíduo que possui competências e habilidades que garantem a sua empregabilidade.

O processo de reestruturação produtiva, exigindo novos padrões de produção acumulação e consumo e o imenso descompasso entre a crescente acumulação de riquezas e o acirramento da pobreza, impõem a definição de estratégias traçadas em âmbito internacional pelos organismos multilaterais.

Estas estratégias visam, por um lado, propiciar condições materiais efetivas de produção capitalista dentro do atual padrão tecnológico, ou seja, de qualificação da força de trabalho, sobretudo. Por outro lado, visam atenuar as disparidades sociais e conter as possibilidades de conflito. (OLIVEIRA, 2000, p. 308)

Nessa perspectiva, à educação coloca-se um duplo objetivo: qualificação para o trabalho e integração/coesão social. Ao mesmo tempo em que é requisito fundamental à formação para o trabalho, para desenvolver maior capacidade de adaptabilidade às mudanças do mundo do trabalho, também possibilita o acesso a um mínimo de conteúdos à grande parcela da população que se vê excluída do emprego formal e regulamentada, dando-lhe perspectivas de encontrar ocupações alternativas (trabalho informal ou autônomo). Além disso, a educação pode colaborar para atenuar os conflitos sociais, na medida em que pode retirar da marginalidade setores economicamente excluídos. "Essa dupla função da educação é que explica tanta atenção voltada agora para a organização e gestão dos sistemas públicos de ensino em todo o mundo, notadamente nos países em desenvolvimento" (OLIVEIRA, 2000, p. 308-309). Assim, a educação passa a ser um requisito indispensável ao sucesso pessoal e profissional do indivíduo.

Observamos que o destaque que aqui colocamos na TCH decorre de nossa compreensão de que, apesar de ser propagada a necessidade de o sistema educacional adequar-se às mudanças econômicas, culturais e tecnológicas, em particular às novas necessidades do mundo do trabalho, o que de fato constatamos é a utilização velada dessa teoria como norteadora das reformas educacionais. Contudo, como demonstrou Frigotto (1995), a TCH incorporou outros elementos em virtude das mudanças políticas e econômicas ocorridas nestes últimos anos no nível global. Mas o que queremos destacar é 
que a forma como as elites vêem a educação não parece ter sofrido alterações. Estas não consideram a educação como um direito a ser assegurado para todos os cidadãos. Continuam vendo-a apenas como um dispositivo a serviço do seu processo de acumulação e, por isso, sua proposta de educação não é, portanto, aquela que interessa à maioria da população.

Num contexto de reestruturação produtiva, de produção flexível e crescimento da competitividade internacional, a TCH ressurge das cinzas, só que desta vez vem acompanhada de todo o substrato que dá sustentação à acumulação flexível, bem como das recomendações de eficiência e produtividade presentes no referencial neoliberal.

Retomando sua crítica a esta teoria, Frigotto (1997) analisa o quanto este reaparecimento está ligado à crise pela qual passa o capital na sua versão globalizada, e como os vários conceitos considerados portadores de novos significados operam como instrumentos ideológicos, cujo objetivo é ocultar o exacerbamento da exploração capitalista neste final de século. Para mostrar esta investida do capital no campo educacional, o autor argumenta que as mudanças na conjuntura política internacional marcada, principalmente, pelo fim do socialismo real e, ao mesmo tempo, por novas teorias que apontam para o "fim da história", bem como para o desaparecimento da classe trabalhadora, compõem um conjunto de elementos que favorecem o surgimento de teorizações no campo educacional, definindo as políticas educacionais de forma que elas atendam aos interesses dos setores capitalistas.

Essas teorizações, fundadas num raciocínio economicista e que ocupam centralidade nos discursos governamentais, reforçam o ideal de política educacional tomada como solução para assegurar o acesso de todos à sociedade do conhecimento e da informação, à adaptação e integração às novas demandas dessa sociedade.

$\mathrm{Na}$ atualidade, tal racionalidade continua fortemente presente no ideário de nossos formuladores e gestores de políticas públicas, como temos observado no caso de Santa Catarina. Destacamos que no ano de 2009, o governo catarinense solicitou à Organização para a Cooperação e Desenvolvimento Econômico (OCDE) que "empreendesse uma análise independente sobre o sistema educacional e que formulasse opções com vista à elaboração de políticas, a curto e médio prazo, com o objetivo de desenvolver o seu capital humano" (OCDE, 2010, p.3; grifo nosso).

Note-se que a idéia de formação de capital humano via desenvolvimento de políticas educativas continua no âmbito das preocupações dos governantes, atualmente tão envoltos com a implantação de reformas nesse setor. Reformas que, segundo Dale (2001), ocorrem em diferentes países e que estão muito mais voltadas à busca de uma "nova governabilidade" dos sistemas públicos de ensino, tendo pouco a ver com as questões propriamente educativas (DALE, 2001). O que está em jogo, portanto, são as necessidades de recomposição das condições gerais da produção capitalista, que, no caso da educação pública, diz respeito ao papel que a mesma pode desempenhar no controle do processo de formação das novas gerações de trabalhadores.

\section{Considerações finais}

Por fim, na década de 1960 no Brasil e no estado de Santa Catarina é possível afirmar que o que marcou o caráter das políticas educacionais foi a sua vinculação aos projetos desenvolvimentistas implementados pelos seus respectivos governos. À política educacional foi reservada importante função no processo de modernização (primordialmente) econômica, segundo uma perspectiva de educação que reforça seu papel 
no desenvolvimento econômico e na integração social, como uma alternativa para resolver os problemas de exclusão social e de desemprego, servindo para alimentar um modelo perverso e excludente de desenvolvimento.

Pautado num discurso hegemônico que afirmava que pela qualificação - pela via da escolarização -, aos indivíduos estariam garantidas as condições para sua inserção no mercado de trabalho e melhoria das suas condições de vida, a política educacional do período assumiu um caráter economicista, tendo como base teórica a TCH. Uma teoria que reforça as noções de desenvolvimento como progresso técnico, aliado ao investimento em recursos humanos, contribuindo amplamente para disseminar a crença na educação como instrumento de distribuição de renda e equalização social. Tal raciocínio monetarista serviu para justificar os ajustes e reformas que atingiram o sistema educacional brasileiro na década.

Constatamos que a política proposta e sistematizada na legislação do ensino (leis, decretos, resoluções) e no planejamento global da educação teve seus contornos influenciados pela conjuntura econômica do período. Essa política foi expressão dos debates e das propostas que já estavam sendo disseminadas pelo MEC com a colaboração dos organismos internacionais para o conjunto da sociedade brasileira. $\mathrm{O}$ debate e as propostas articulavam-se à idéia da contribuição fundamental que a educação poderia exercer no sentido de inscrever o Brasil no rol dos países desenvolvidos.

Ao adotar a concepção economicista de educação, a política educacional ignora o fato de que a desigualdade social existente na sociedade não se explica exclusivamente por uma distribuição desigual do conhecimento, mas sim pelas próprias características do modelo econômico capitalista que tende a concentrar, de forma contínua, a riqueza historicamente produzida. Os propagadores da TCH intencionalmente "esquecem" que o próprio acesso à produção cultural é reflexo das desigualdades geradas por este modelo de produção. Ignoram que a educação atua como atividade mediadora no seio da prática social global, sendo um elemento de mediação no desenvolvimento de uma determinada sociedade. E que, ao afirmar-se esse caráter mediador da educação afirma-se o seu caráter instrumental, o que significa admitir que o que se passa em seu interior não se explica por si mesmo, mas ganha este ou aquele sentido, produz este ou aquele efeito social dependendo das forças sociais que nela atuam e com as quais ela se vincula (SAVIANI, 2005).

No período histórico aqui objeto de discussão, o discurso de aliar educação e desenvolvimento tem seu papel ideológico. Ele cumpre a função de livrar o sistema capitalista de maiores críticas.

\footnotetext{
No contexto atual, no qual há uma forte diminuição do poder político dos Estados-nações, decorrentes do "fenômeno" da globalização, o capital busca uma nova interpretação ideológica, capaz de justificar as relações de poder e de exploração. Neste sentido, como uma continuidade da Teoria do Capital Humano, mas englobando novas características, próprias de uma economia globalizada, surge o discurso de que vivemos numa "Sociedade do Conhecimento" e que, por conseguinte, neste novo contexto, são exigidas dos trabalhadores novas qualificações e habilidades que lhes permitam inserir-se no mercado de trabalho, competindo de forma igualitária com outras pessoas. (OLIVEIRA, 2001, p. 27)
}

Segundo a ótica liberal, o sistema educacional teria um papel de gerar oportunidades de ascensão social, garantindo a "igualdade de oportunidades". Esse discurso não se 
sustenta, pois o desenvolvimento de uma nação se dá por um conjunto de fatores, e a educação escolar não pode ser encarada como panacéia para todos os males. Não bastaria apenas o investimento na formação e qualificação da força de trabalho, para haver um maior acesso à riqueza produzida por parte da população. A possibilidade de distribuição desta riqueza depende, exclusivamente, de uma mudança das relações de poder e de uma modificação radical do sistema de produção. (FRIGOTTO, 1995)

Por fim, corroborando a tese aqui apresentada - a reedição da TCH como inspiradora da política educacional brasileira a partir dos anos de 1990, recentemente alguns estudos (MOTTA, 2008; MARTINS, 2007; LIMA, 2007; LIMA, MARTINS, 2005) vêm apontado o quanto a reedição desse estatuto teórico, se apresenta no contexto de humanização do capitalismo, na perspectiva de colaborar para a "transformação social". No entanto, afirmam os autores, esta transformação não significa uma mudança estrutural da sociedade, mas uma melhoria gradual na distribuição de renda (alívio da pobreza), na adaptação às incertezas, o que tornou as mudanças nos processos escolares necessárias.

Destacamos, por exemplo, o estudo de Motta (2008) que demonstra que o processo de redefinição das estratégias de legitimação social do Estado brasileiro, ocorrido em meados dos anos de 1990, estava fundamentado no programa político-econômico da Terceira Via ${ }^{4}$. A concepção hegemônica — o neoliberalismo da Terceira Via, definiu como uma das funções da aparelhagem estatal a educação escolar e política da população para garantir a "coesão social". A educação, assim, foi reconhecida como uma importante estratégia para formar diferentes intelectuais que vão aprofundar as relações humanas a partir dos pressupostos da nova sociabilidade e a partir da tese do individualismo reformado. Como afirma um dos principais intelectuais do projeto político da Terceira Via, Anthony Giddens 5 ,

[...] a principal força do desenvolvimento de capital humano obviamente deve ser a educação. É o principal investimento público que deve estimular a eficiência econômica e a coesão cívica. [...] A educação precisa ser redefinida de forma a se concentrar nas capacidades que os indivíduos poderão desenvolver ao longo da vida. (GIDDENS, 2001, p. 78)

Com tal proposição, a Terceira Via retomou os pressupostos da $\mathrm{TCH}$, atribuindo-lhe uma nova roupagem. Como destacam Lima e Martins (2005), ao mesmo tempo trouxe a noção de "capital social", difundida por intelectuais estadunidenses (como Francis Fukuyama, James S. Colleman, Robert Putnam). Empregada nos documentos de organismos internacionais, como a Organização das Nações Unidas (ONU) e o BM, designa a capacidade de articulação dos grupos de pessoas ou de toda uma comunidade na busca de soluções para seus problemas mais imediatos; ou seja, a noção de capital social é utilizada na perspectiva de orientar as políticas sociais focalizadas, ao lado das noções de "pobreza" e de "desenvolvimento social sustentado" (LIMA; MARTINS, 2005, p.62-63).

Estatutos teóricos, como a $\mathrm{TCH}$, colaboram para enfatizar o papel da escola na construção da cidadania ativa, que permita aos indivíduos identificar e posicionar-se diante das transformações em curso, incorporando-se ao trabalho precarizado e à sociedade vigente. 


\section{Referências}

AGUIAR, Letícia Carneiro. Política educacional e a criação do curso de Pedagogia em Santa Catarina. Palhoça: Editora da Unisul, 2008.

BRASIL. Ministério da Educação e Cultura. Instituto Nacional de Estudos e Pesquisas. Assistência Técnica aos Estados no campo da Educação. CEOSEs, Brasília: MEC/INEP, 1967.

CRUZ, Marta Vieira. Brasil nacional-desenvolvimentista (1946-1964). Disponível em: $<$ http://www.histedbr.fae.unicamp.br/navegando/artigos_titulos.html>. Acesso em: 15 maio 2008.

CUNHA, Luiz Antonio. Educação e desenvolvimento social no Brasil. Rio de Janeiro: Francisco Alves, 1980.

DALE, Roger. Globalização e educação: demonstrando a existência de uma "cultura educacional mundial comum" ou localizando uma "agenda globalmente estruturada para a educação”. Educação, Sociedade \& Culturas, Porto, n.16, p.133-169, 2001.

DUTRA, A.; PEREIRA, Luzete Adelaide; AURAS, Marli. O avanço progressivo: uma proposta pedagógica de avaliação do rendimento escolar distintiva da reorganização do ensino em Santa Catarina. Cadernos do CED, Florianópolis, Ano I, n. 1⁄2, 1984.

FEDERAÇÃO DAS INDÚSTRIAS DO ESTADO DE SANTA CATARINA - FIESC. Documento Básico do Seminário Sócio-Econômico. Florianópolis: Biblioteca da FIESC, 1960.

FRIGOTTO, Gaudêncio. Educação e a crise do capitalismo real. São Paulo: Cortez, 1995.

Os delírios da razão: crise do capital e metamorfose conceitual no campo educacional. In: GENTILI, Pablo (Org.). Pedagogia da exclusão: o neoliberalismo e a crise da escola pública. Petrópolis: Vozes, 1997.

GIDDENS, Anthony. A Terceira Via. Reflexões sobre o impasse político atual e o futuro da social-democracia. Tradução de Maria Luiza Borges. Rio de Janeiro: Record, 2001.

GOULARTI FILHO, Alcides. Formação econômica de Santa Catarina. Florianópolis: Cidade Futura, 2002.

LEITE, Márcia de Paula. Qualificação, desemprego e empregabilidade. São Paulo em Perspectiva, São Paulo, v.11, n.1, jan./mar. 1997, p. 64-69.

LIMA, Kátia Regina de Souza. Contra-reforma na educação superior: de FHC a Lula. São Paulo: Xamã, 2007.

LIMA, Kátia Regina de Souza, MARTINS, A. S. Pressupostos, princípios e estratégias. In: NEVES, Lúcia M.W. (Org). A nova pedagogia da hegemonia. Estratégias do capital para educar o consenso. São Paulo: Xamã, 2005, p. 43-68.

MARTINS, André Silva. Burguesia e a nova sociabilidade: estratégias para educar o consenso no Brasil Contemporâneo. Tese (Doutorado em Educação). Faculdade de Educação, Universidade Federal Fluminense, Rio de Janeiro, 2007.

MICHELS, Ido Luiz. Crítica ao modelo catarinense de desenvolvimento. Campo Grande: Editora da UFMS, 1998. 
MOTTA, Daniela. A formação de professores a distância para a nova sociabilidade: análise do "Projeto Veredas" de Minas Gerais. Tese (Doutorado em Educação). Faculdade de Educação, Universidade Federal Fluminense, Rio de Janeiro, 2008.

OLIVEIRA, Dalila Andrade. Educação básica: gestão do trabalho e da pobreza. Petrópolis: Vozes, 2000.

OLIVEIRA, Dalila Andrade; DUARTE, Adriana. Política educacional como política social: uma nova regulação da pobreza. Perspectiva, Florianópolis, v. 23, n. 2, p. 279-301, 2005.

OLIVEIRA, Ramon de. A teoria do capital humano e a educação profissional brasileira. Boletim Técnico do SENAC, Rio de Janeiro, v. 27, n. jan./abr., p. 26-37, 2001.

ORGANIZAÇÃO PARA A COOPERAÇÃO E DESENVOLVIMENTO ECONÔMICO. OCDE. Avaliação de Políticas Nacionais de Educação - Estado de Santa Catarina, Brasil. 2010.

PROGRAMA DAS NAÇÕES UNIDAS PARA O DESENVOLVIMENTO. PNUD. Informe Regional sobre Desarrollo Humano para América Latina y el Caribe. Actuar sobre el futuro, romper la transmisión intergeneracional de la desigualdad. 2010.

Disponível em: http://www.idhalc-actuarsobreelfuturo.org/site/index.php. Acesso em: nov. 2010.

ROMANELLI, Otaíza. História da Educação no Brasil (1930-1975). 27. ed. Petrópolis: Vozes, 2002.

SAVIANI, Dermeval. Educação: do senso comum à consciência filosófica. 5. ed. São Paulo: Cortez; Autores Associados, 1985.

Pedagogia histórico-crítica. São Paulo: Autores Associados, 2005.

SANTA CATARINA. Governador Celso Ramos: 1961/1966. Mensagens Anuais apresentadas à Assembléia Legislativa, 4ª e 5ª em 15 de março de 1965. Florianópolis, 1965, p. 13.

. Sobre as Condições do Processo Educacional de Santa Catarina. Florianópolis: FESC/UDESC/FAED/CEPE, 1967.

Programa de Governo do Estado de Santa Catarina. Florianópolis, v. II (separata), n. 5 - Educação, mar. 1969a.

Plano Estadual de Educação 1969-1980. Florianópolis, 1969b.

SCHULTZ, Theodoro W. O valor econômico da educação. Rio de Janeiro: Zahar, 1962.

WARDE, Miriam Jorge. Educação e estrutura social: a profissionalização em questão. 2. ed. São Paulo: Cortez \& Moraes, 1984.

Notas:

1 Em novembro de 1989, reuniram-se na capital dos Estados Unidos funcionários do governo norteamericano e dos organismos financeiros internacionais ali sediados - Fundo Monetário Internacional (FMI), Banco Mundial e Banco Interamericano de Desenvolvimento - especializados em assuntos latinoamericanos. O objetivo do encontro, convocado pelo Institute for International Economics, sob o título "Latin American Adjustment: How Much Has Happened?”, era proceder a uma avaliação das reformas econômicas empreendidas nos países da região. Para relatar a experiência de seus países também estiveram presentes 
diversos economistas latino-americanos. Às conclusões dessa reunião é que se daria, subseqüentemente, a denominação informal de "Consenso de Washington".

2 Conferência de Jomtien é um nome genérico dado à conferência realizada na cidade de Jomtien, na Tailândia, em 1990, denominada Conferência Mundial sobre Educação para Todos, cujo objetivo era estabelecer compromissos mundiais para garantir a todas as pessoas os conhecimentos básicos necessários a uma vida digna, condição insubstituível para o advento de uma sociedade mais humana e mais justa. Participaram das discussões a UNESCO e a UNICEF, com apoio do Banco Mundial e de várias outras organizações intergovernamentais, regionais e organizações não-governamentais (ONGs). A Conferência de Jomtien resultou na elaboração de um dos documentos mundialmente mais significativos em educação, lançados a partir de sua realização: a Declaração de Jomtien ou Declaração Mundial sobre Educação Para Todos. Esse documento inclui, entre outras questões, as metas a serem atingidas relativamente à educação básica e os compromissos dos Governos e outras entidades participantes. Dessa forma, em seqüência à Conferência Mundial, os países foram incentivados a elaborar Planos Decenais de Educação Para Todos, em que as diretrizes e metas do Plano de Ação da Conferência fossem contempladas. Em decorrência de compromisso assumido na Conferência de Jomtien, foi elaborado no Brasil o Plano Decenal de Educação para Todos, cuja meta principal era assegurar, em dez anos (1993 a 2003), às crianças, jovens e adultos, os conteúdos mínimos em matéria de aprendizagem que respondam às necessidades elementares da vida contemporânea (universalização da educação fundamental e erradicação do analfabetismo).

${ }^{3}$ O estudo traz o cálculo do IDH-D (Índice de Desenvolvimento Humano ajustado à Desigualdade) que "penaliza" as diferenças de rendimentos, de escolaridade e de saúde. O texto aborda o fosso entre vários grupos (homens e mulheres, zona rural e urbana, brancos, negros e índios) e sob vários aspectos, mas a medida mais sintética apresentada é o novo IDH.

4 O programa político da Terceira Via (também denominada centro radical, centro-esquerda, nova esquerda, nova social-democracia, social-democracia modernizadora ou governança progressista) se estendeu por todas as áreas e abrange os principais temas em debate na sociedade. As teses da Terceira Via foram sistematizadas pelo sociólogo britânico Anthony Giddens, um dos principais articuladores políticos do novo trabalhismo inglês e também da Cúpula (Mundial) da Governança Progressiva. Ao mesmo tempo em que criticou o neoliberalismo, a Terceira Via reconheceu a pertinência de seus pressupostos, necessários à modernização do Estado, uma vez que políticas como o Welfare State, propostas pela "velha esquerda" — a social-democracia clássica-, geraram mais problemas do que foi capaz de resolver. Segundo Giddens (A Terceira Via. reflexões sobre o impasse político atual e o futuro da social-democracia. Tradução de Maria Luiza X. de A. Borges. Rio de Janeiro: Record, 2001), a gravidade do neoliberalismo estaria no abandono das medidas de caráter social, afetando, portanto, a "coesão social”. As críticas também são dirigidas ao socialismo. O fim do regime soviético significou a morte do socialismo que, entre outras observações, teria uma concepção instrumental da história e da natureza e uma concepção redutora de democracia. Assim, dada a "inviabilidade histórica" do socialismo e as inadequações do neoliberalismo e da socialdemocracia clássica, foi necessário criar uma nova plataforma política, econômica e social, ou seja, uma nova ideologia, uma nova sociabilidade, na qual a educação torna-se imprescindível como estratégia política para a obtenção do consenso em torno dessa nova ordem. Ao partir do pressuposto da morte do socialismo e da defesa do capitalismo como sistema social, assumiu o "mercado" como "lei natural, universal e inevitável". Dessa forma, as classes sociais e as contradições de classe teriam desaparecido em favor de uma política sem antagonistas — o "Estado sem inimigos" —, numa suposta possibilidade de harmonia social e de reforma do capitalismo. Essa "fatal inalterabilidade" do atual estágio de desenvolvimento do capital, expressa o consenso ao qual todos devemos nos resignar, onde não existem ou mesmo não importam as classes e as contradições de classe.

${ }^{5}$ Anthony Giddens é diretor da London School of Economics e professor da Universidade de Cambridge. É considerado um dos principais teóricos do Novo Trabalhismo britânico e autor ou editor de mais de trinta livros, entre eles Para além da esquerda e da direita e A Terceira Via, que influenciaram o debate sobre o futuro da social-democracia em muitos países. Agraciado com muitos títulos honoríficos e condecorações em vários países, recebeu também a Ordem do Cruzeiro do Sul, no Brasil.

Artigo recebido em: 09/09/2010

Aprovado em: $\quad 9 / 12 / 2010$ 